\title{
The Significance of Neutrophil-to-Lymphocyte Ratio and Combined Chemoradiotherapy in Patients Undergoing Bladder Preservation Therapy for Muscle-Invasive Bladder Cancer
}

This article was published in the following Dove Press journal:

Cancer Management and Research

\author{
Chun-Te $\mathrm{Wu}^{1,2}$ \\ Yun-Ching Huang ${ }^{2,3}$ \\ Wen-Cheng Chen ${ }^{2,4}$ \\ Miao-Fen Chen (iD ${ }^{2,4}$ \\ 'Department of Urology, Chang Gung \\ Memorial Hospital at Keelung, Keelung, \\ Taiwan; ${ }^{2}$ Chang Gung University, College \\ of Medicine, Taoyuan, Taiwan; \\ ${ }^{3}$ Department of Urology, Chang Gung \\ Memorial Hospital at Chiayi, Chiayi, \\ Taiwan; ${ }^{4}$ Department of Radiation \\ Oncology, Chang Gung Memorial \\ Hospital at Chiayi, Chiayi, Taiwan
}

Background: Bladder-sparing treatment has been developed with the aim of preserving bladder function. However, considerable controversy remains regarding the effectiveness of organ preservation strategies. Accordingly, we investigated factors influencing the prognosis of muscle-invasive bladder cancer (MIBC) patients who received bladder-sparing treatment. Materials and Methods: In the study, we retrospectively reviewed 193 patients who were newly diagnosed with MIBC and received bladder-sparing treatment from 2006 to 2013 in our hospital.

Results: The 5-year overall survival, progression-free survival (PFS) and bladderpreservation survival rates after diagnosis were $64.7 \%, 52.1 \%$, and $64 \%$, respectively. The presence of hydronephrosis, advanced stage and not achieving complete response were associated with a marked reduction in PFS. Treatment with an adequate dose of combined chemoradiotherapy (CCRT) (chemotherapy $\geq 2$ cycles combined with radiotherapy dose $\geq 56 \mathrm{~Gy}$ ) significantly improved the complete response (CR), 5-year bladder-preservation survival, and PFS rates, particularly for patients with good performance status. The 5-year bladder-preservation survival rates for $\mathrm{CR}$ and non-CR patients were $75 \%$, and $21 \%$, respectively. Furthermore, higher pre-treatment neutrophil-to-lymphocyte ratio (NLR) $(\geq 3)$ and lower hemoglobin $(\leq 12)$ were significantly associated with lower CR rate, increased risk of loco-regional recurrence and reduced bladder-preservation survival rate. Multivariable Cox regression analysis based on different co-variables showed that pretreatment NLR was an independent prognostic factor for PFS when MIBC patients were stratified by clinical stage and the doses of CCRT.

Conclusion: In MIBC patients with bladder-sparing treatment, adequate doses of CCRT and low NLR were found to be correlated with better PFS. We suggest the use of NLR as a clinical biomarker for the prognosis of MIBC and guidance of treatment decisions.

Keywords: MIBC, bladder-sparing, radiotherapy, recurrence, NLR

\section{Introduction}

Most patients with bladder cancer present with superficial tumors that are limited to the mucosa and submucosa; however, approximately $30 \%$ present with muscle invasion. The current standard of care for muscle-invasive bladder cancer (MIBC) is either radical cystectomy (RC) or, in selected patients, bladder preservation. ${ }^{1-3} \mathrm{RC}$ comprises the standard and most common treatment offered to patients with MIBC. RC typically provides excellent locoregional control of the
Correspondence: Miao-Fen Chen Department of Radiation Oncology, Chang Gung Memorial Hospital at Chiayi, Taiwan

Email miaofen@adm.cgmh.org.tw 
disease. Contemporary cystectomy series of patients with MIBC have reported 5-year overall survival (OS) rates ranging from $40 \%$ to $60 \%$, according to clinical staging. ${ }^{4,5}$ However, the treatment is associated with significant procedure-related morbidity, leading to poor quality of life. ${ }^{6,7}$ Bladder-sparing treatment was developed with the aim of preserving bladder function. ${ }^{3,8}$ Several bladder-preservation options exist, including transurethral resection of bladder tumor (TURBT), radiation therapy (RT) alone, or combined modality treatment (CMT). CMT consists of maximal TURBT, RT, and concurrent chemotherapy $(\mathrm{C} / \mathrm{T})$. Several Radiation Therapy Oncology Group (RTOG) studies have demonstrated that this CMT approach in patients with MIBC can achieve high rates of complete tumor response, bladder preservation in the majority of patients, and survival rates similar to those observed in contemporary RC series. ${ }^{9,10}$ However, considerable controversy remains regarding the effectiveness of bladder-sparing strategies. Factors influencing the treatment decision can include patients' baseline characteristics, tumor involvement, and the treatment techniques used.

Routine blood examination is a rapid and convenient clinical examination that can reflect a patient's inflammatory status and other blood condition. Studies have shown that inflammatory responses play an important role in tumor activity and invasiveness. ${ }^{11}$ The neutrophil-tolymphocyte ratio (NLR) is a systemic inflammatory and immunologically marker. ${ }^{12,13}$ An elevated NLR in many solid tumors has been associated with reduced survival including urothelial carcinoma. ${ }^{14,15}$ However, the predictive value of the NLR in MIBC with bladder-sparing treatment requires further investigation. In addition, some cancer patients have poor prognosis with a low preoperative hemoglobin $(\mathrm{Hb})$ level. Accordingly, we retrospectively analyzed the clinical outcomes of MIBC patients with bladder-sparing treatment to explore prognostic factors and the predictive role of blood parameters including
A

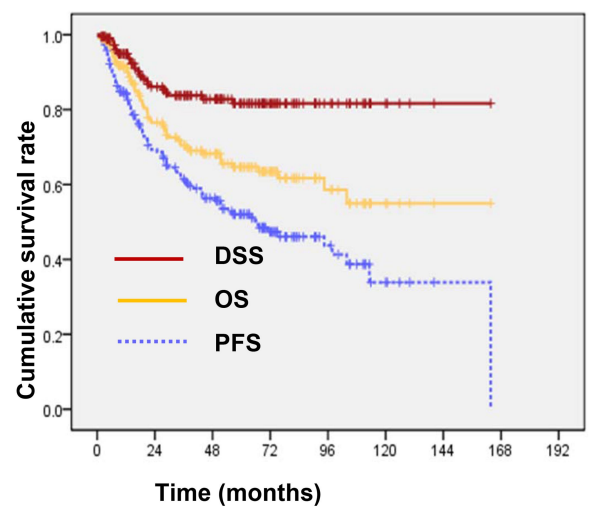

C

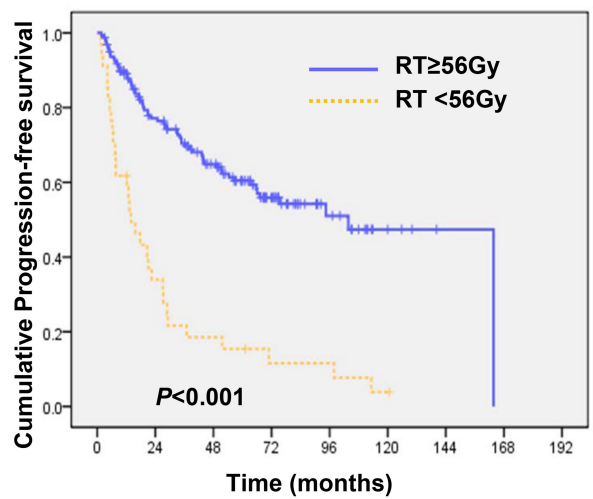

B

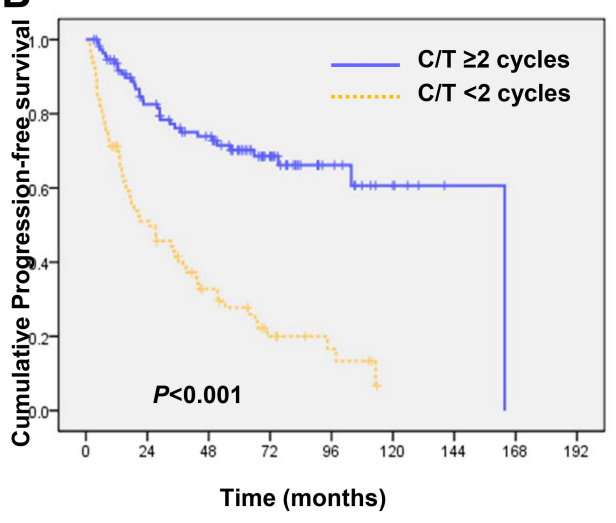

D

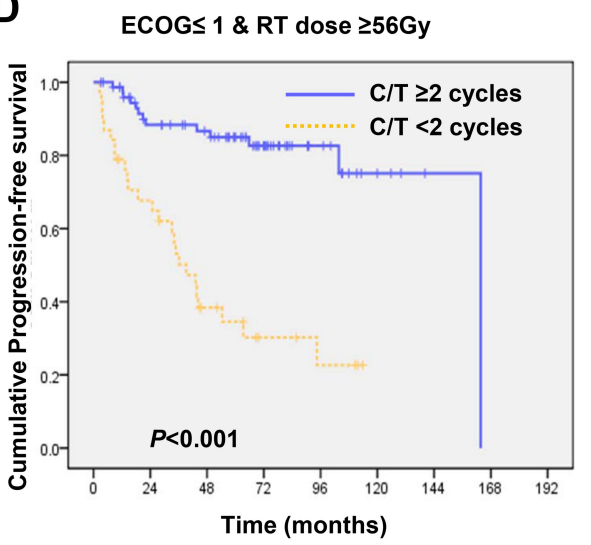

ECOG>1 \& RT dose $\geq 56 \mathrm{~Gy}$

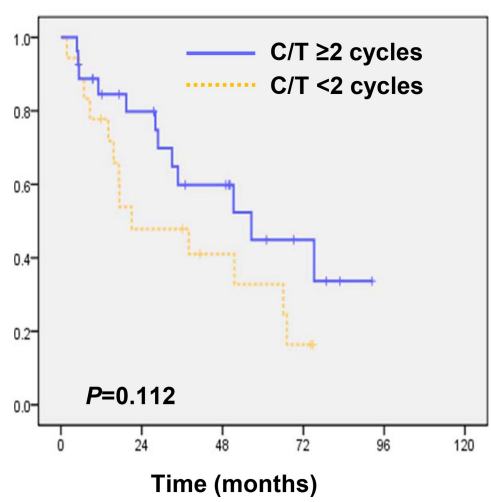

Figure I Survival of MIBC patients treated with bladder-sparing treatment. (A) Kaplan-Meier survival curves of the patients with MIBC in total; and the PFS differences according to (B) the cycles of chemotherapy and (C) the dose of RT. Furthermore, the PFS differences according to (D) the cycles of chemotherapy in patients stratified with ECOG and the dose of RT. 


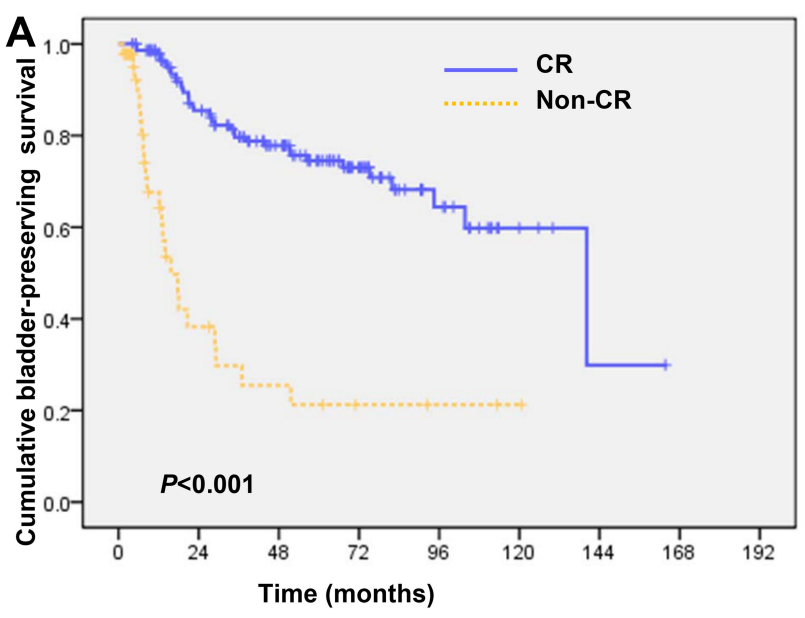

B

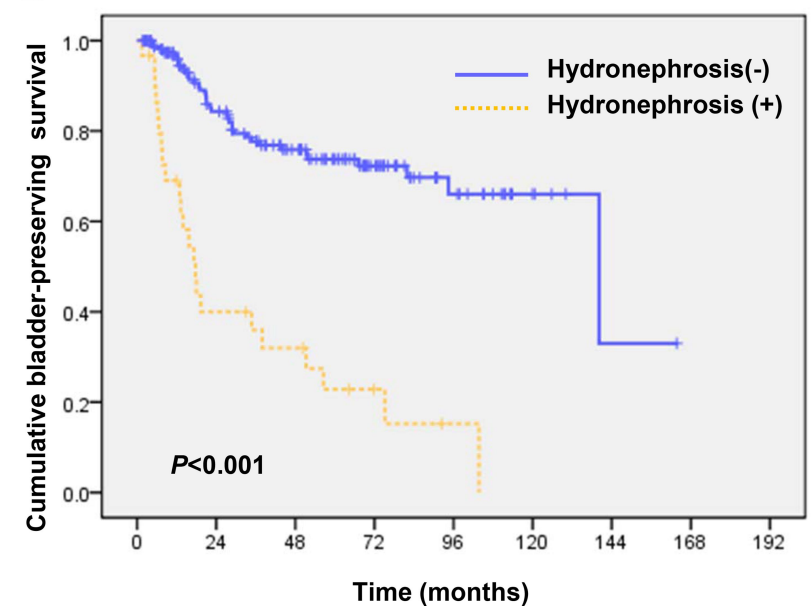

C

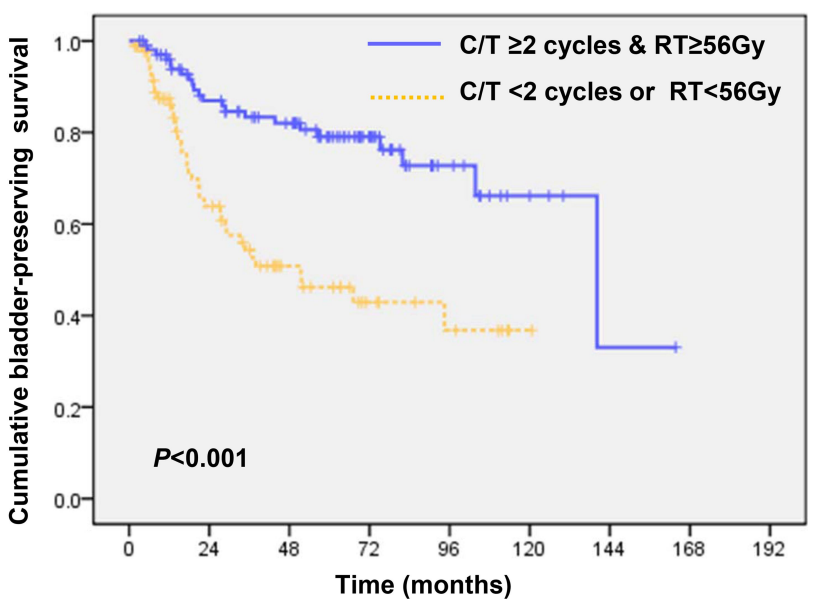

Figure 2 Correlations between the bladder-preservation survival and the response to bladder-sparing treatment Kaplan-Meier survival curves of the patients with MIBC; and the difference of bladder-preserving survival according to $(\mathbf{A})$ the response to bladder-sparing treatment, (B) the presence of hydronephrosis, and (C) the doses of chemotherapy and RT.

NLR and $\mathrm{Hb}$. It is hoped that the data can assist clinicians and patients in making informed decisions regarding treatment options.

\section{Materials and Methods}

\section{Study Population}

This retrospective study was approved by the institutional review board of Chang Gung Memorial hospital (No. 201801752B0), and a waiver of informed consent was obtained. This study adhered to strict confidentiality guidelines and conducted in accordance with the Declaration of Helsinki. Patients with non-muscle-invasive bladder cancer (NMIBC), lymph node metastasis above the common iliac nodes or other distant metastasis, or another cancer diagnosis at the time of MIBC diagnosis were excluded from this study. We enrolled 193 patients with MIBC who had histologically confirmed diagnosis of urothelial carcinoma and received curative-intent bladder-sparing treatment from 2006 to 2013 using the data of cancer registry and death registration in our Hospital. The diagnosis of bladder cancer was made based on TURBT histological specimens. The treatment for bladder cancer was made according to the guidelines proposed by the oncology team at our hospital. Surgery is considered for all physiologically fit patients with localized MIBC. If surgery was contraindicated or the patients refused it, they received bladder-sparing treatment. Anonymized patient data were collected regarding patients' demographic details, disease characteristics, and treatment outcome until Dec, 2018. The study enrolled patients who were treated with maximal TURBT followed by RT with or without concurrent chemotherapy for MIBC. The RT protocols generally include initial RT of the whole bladder and pelvic lymph nodes with an initial dose of 40-45 Gy, followed by consolidation RT of the bladder tumor with 
Table I Analysis to Determine Factors Associated with the CR Rate

\begin{tabular}{|c|c|c|c|}
\hline & \multicolumn{2}{|c|}{ No. of Patients } & \multirow[b]{2}{*}{$p$ value } \\
\hline & CR & No CR & \\
\hline Patients & I 48 (I00\%) & 45 (100\%) & \\
\hline $\begin{array}{l}\text { Pathologic grade } \\
\text { Low } \\
\text { High } \\
\text { Unknown }\end{array}$ & $\begin{array}{l}18(12 \%) \\
129(87 \%) \\
1(1 \%)\end{array}$ & $\begin{array}{l}4(9 \%) \\
40(89 \%) \\
I(2 \%)\end{array}$ & 0.568 \\
\hline $\begin{array}{l}\text { Clinical T stage } \\
\text { T2 } \\
\text { T3-4 }\end{array}$ & $\begin{array}{l}107(72 \%) \\
4 \mid(28 \%)\end{array}$ & $\begin{array}{l}26(58 \%) \\
19(42 \%)\end{array}$ & 0.066 \\
\hline $\begin{array}{l}\text { Clinical N stage } \\
\text { N0 } \\
N(+)\end{array}$ & $\begin{array}{l}\text { I } 40(95 \%) \\
8(5 \%)\end{array}$ & $\begin{array}{l}39(87 \%) \\
6(13 \%)\end{array}$ & 0.073 \\
\hline $\begin{array}{l}\text { Hydronephrosis } \\
\text { No } \\
\text { Yes }\end{array}$ & $\begin{array}{l}133(90 \%) \\
15(10 \%)\end{array}$ & $\begin{array}{l}30(67 \%) \\
15(33 \%)\end{array}$ & $<0.00 I^{*}$ \\
\hline $\begin{array}{r}\text { RT dose } \\
<56 \mathrm{~Gy} \\
\geq 56 \mathrm{~Gy}\end{array}$ & $\begin{array}{l}5(4 \%) \\
143(96 \%)\end{array}$ & $\begin{array}{l}29(64 \%) \\
16(36 \%)\end{array}$ & $<0.00 I^{*}$ \\
\hline $\begin{array}{l}\text { Chemotherapy } \\
<2 \text { cycles } \\
\geq 2 \text { cycles }\end{array}$ & $\begin{array}{l}48(32 \%) \\
100(68 \%)\end{array}$ & $\begin{array}{l}32(7 \mid \%) \\
13(29 \%)\end{array}$ & $<0.00 I^{*}$ \\
\hline $\begin{array}{l}\mathbf{H b} \\
\quad \leq 12 \\
>12\end{array}$ & $\begin{array}{l}69 \\
79\end{array}$ & $\begin{array}{l}30 \\
15\end{array}$ & $0.019 *$ \\
\hline $\begin{array}{r}\text { NLR } \\
<3 \\
\geq 3\end{array}$ & $\begin{array}{l}95(64 \%) \\
53(36 \%)\end{array}$ & $\begin{array}{l}3(7 \%) \\
42(93 \%)\end{array}$ & $<0.00 I^{*}$ \\
\hline
\end{tabular}

Notes: *Statistical significance.

a dose of $60-64$ Gy. Patients who received RT with $\geq 50$ Gy were included in the retrospective study. Use of combined chemoradiotherapy (CCRT) was defined as chemotherapy administered within 3 months of TURBT. The chemotherapy regimen used for bladder-sparing treatment in our hospital was cisplatin-based chemotherapy. The combined $\mathrm{C} / \mathrm{T}$ regimen was usually Cisplatin $50 \mathrm{mg} / \mathrm{m} 2$ intravenously (i.v.) on Day 1 and $5-\mathrm{FU} 500 \mathrm{mg} / \mathrm{m} 2$ + Calcium Folinate $50 \mathrm{mg}$ continuous i.v. infusion on Day1 3. The scheduled C/T course was repeated every 21 days 2-4 times, according to the patient's tolerance as judged by a medical oncologist. Cystoscopic assessment with biopsy of the tumor site and voided urine cytology were performed at bladder-sparing treatment completion to assess the treatment response. Clinical complete response (CR) was defined as no tumor visible on cystoscopy, negative tumor site biopsy, and negative urine cytology. Patients were observed at 3-month intervals for the first 2 years and every 6 months thereafter. The neutrophil-tolymphocyte ratio (NLR) was calculated by dividing the absolute neutrophil count by the absolute lymphocyte count. To assess the predictive value of the NLR, it was redefined as a binary variable by Contal and O'Quigley's method $^{16}$ for predicting progression-free survival (PFS) of the 193 MIBC patients (Table S1). Accordingly, MIBC patients were divided into two groups: the high (NLR $\geq 3$ ) and low $(\mathrm{NLR}<3)$ groups.

\section{Statistical Analysis}

We used the Kaplan-Meier method to calculate survival and the Log rank test to compare differences in survival between the two groups, including overall survival (OS), progression-free survival (PFS) (the time elapsed between treatment initiation and tumor progression or death from any cause), disease-specific survival (DSS), and bladder-preservation survival (the length of time that patients remain alive and have an intact bladder). Finally, Cox proportional hazards models were used to compute hazard ratios with $95 \%$ confidence intervals (CIs) after adjustment for MIBC treatment and clinical characteristics.

\section{Results}

\section{The Relationships Between Clinical} Parameters and Survival in MIBC Patients Treated with Bladder-Sparing Treatment

From 2006 to 2013,193 patients newly diagnosed with MIBC without distant metastasis underwent curative-intent bladder-sparing treatment in our hospital. The follow-up interval ranged from 1.4 to 162.3 months with a median of 37 months. The 5-year OS, DSS, and PFS rates after diagnosis were $64.7 \%, 81.6 \%$, and $52.1 \%$, respectively (Figure 1A). Regarding clinical characteristics, survival analysis showed that older age, poor performance status, clinical T3-4 and lymph node involvement were correlated with reduced PFS. Regarding treatment parameters, chemotherapy $\geq 2$ cycles and $\mathrm{RT}$ dose $\geq 56 \mathrm{~Gy}$ were significant predictors for longer PFS (Figure 1B-C). Furthermore, in the group of patients with RT dose $\geq 56 \mathrm{~Gy}$, chemotherapy $\geq 2$ cycles significantly improved PFS $(p<0.001)$ for patients with $\mathrm{ECOG} \leq 1$, but not for patients with poor performance 
Table 2 Analysis to Determine Factors Associated with NLR

\begin{tabular}{|c|c|c|c|}
\hline & \multicolumn{2}{|c|}{ No. of Patients } & \multirow[b]{2}{*}{$p$ value } \\
\hline & $N L R<3$ & NLR $\geq 3$ & \\
\hline Patients & 98 & 95 & \\
\hline ECOG & & & $<0.00 I^{*}$ \\
\hline$\leq 1$ & 83 & 51 & \\
\hline$>1$ & 15 & 44 & \\
\hline Pathologic grade & & & 0.410 \\
\hline Low & 13 & 9 & \\
\hline High & 84 & 85 & \\
\hline Unknown & I & 1 & \\
\hline Clinical T stage & & & 0.166 \\
\hline $\mathrm{T} 2$ & 72 & 61 & \\
\hline T3-4 & 26 & 34 & \\
\hline Clinical $\mathbf{N}$ stage & & & 0.085 \\
\hline No & 94 & 85 & \\
\hline$N(+)$ & 4 & 10 & \\
\hline Hydronephrosis & & & $<0.00 I^{*}$ \\
\hline No & 93 & 70 & \\
\hline Yes & 5 & 25 & \\
\hline $\mathbf{H b}$ & & & $0.001 *$ \\
\hline$\leq 12$ & 39 & 60 & \\
\hline$>12$ & 59 & 35 & \\
\hline Treatment response ${ }^{\mathrm{b}}$ & & & $<0.001 *$ \\
\hline CR & 95 & 53 & \\
\hline Non-CR & 3 & 42 & \\
\hline 5-yr loco-regional control rate & $87 \%$ & $33.4 \%$ & $<0.001 *$ \\
\hline $\begin{array}{l}5 \text {-yr distant metastasis-free } \\
\text { rate }\end{array}$ & $94.4 \%$ & $68 \%$ & $<0.00 I^{*}$ \\
\hline 5-yr OS & & & $<0.00 I^{*}$ \\
\hline & $89.8 \%$ & $35.3 \%$ & \\
\hline
\end{tabular}

Notes: ${ }^{*}$ Statistical significance. ${ }^{b}=$ Response to bladder-sparing treatment.

status $(\mathrm{p}=0.112)$ (Figure 1D). Therefore, we suggest that adequate doses of CCRT correlated with better PFS, particularly for patients with good performance status.

\section{Outcomes of Bladder Preservation}

In our series, the 5-year bladder-preservation survival rate was $64 \%$. Complete response (CR) to bladder-sparing treatment is a significant factor in the success rate of bladder preservation. In our series, $148(76 \%)$ patients achieved CR by cystoscopic examination. Figure $2 \mathrm{~A}$ shows that the 5 -year bladder-preservation survival rates for $\mathrm{CR}$ and nonCR patients were $75 \%$, and $21 \%$, respectively. Table 1 and Figure $2 \mathrm{~B}-\mathrm{C}$ indicated that adequate doses of CCRT
Table 3 Analysis to Determine Factors Associated with $\mathrm{Hb}$ Level

\begin{tabular}{|c|c|c|c|}
\hline & \multicolumn{2}{|c|}{ No. of Patients } & \multirow[b]{2}{*}{$p$ value } \\
\hline & $H b \leq 12$ & $H b>12$ & \\
\hline Patients & 99 & 94 & \\
\hline ECOG & & & $0.006 *$ \\
\hline$\leq 1$ & 60 & 74 & \\
\hline$>1$ & 39 & 20 & \\
\hline Pathologic grade & & & 0.897 \\
\hline Low & 11 & 11 & \\
\hline High & 87 & 82 & \\
\hline Unknown & I & 1 & \\
\hline Clinical T stage & & & 0.105 \\
\hline $\mathrm{T} 2$ & 63 & 70 & \\
\hline T3-4 & 36 & 24 & \\
\hline Clinical $\mathbf{N}$ stage & & & 0.514 \\
\hline No & 93 & 86 & \\
\hline $\mathrm{N}(+)$ & 6 & 8 & \\
\hline Hydronephrosis & & & 0.302 \\
\hline No & 81 & 82 & \\
\hline Yes & 18 & 12 & \\
\hline Treatment response $^{\mathrm{b}}$ & & & $<0.018^{*}$ \\
\hline CR & 69 & 79 & \\
\hline Non-CR & 30 & 15 & \\
\hline 5-yr loco-regional control rate & $56.6 \%$ & $68.3 \%$ & 0.056 \\
\hline $\begin{array}{l}5 \text {-yr distant metastasis-free } \\
\text { rate }\end{array}$ & $80.6 \%$ & $86.5 \%$ & 0.198 \\
\hline $5-y r$ OS & & & $<0.001 *$ \\
\hline & $49.1 \%$ & $78.7 \%$ & \\
\hline
\end{tabular}

Notes: *Statistical significance.

(chemotherapy $\geq 2$ cycles and RT dose $\geq 56$ Gy) and no hydronephrosis were significantly associated with increased $\mathrm{CR}$ rate and higher 5-year bladder-preservation survival rate. During follow-up for these CR patients, 44 (30\%) developed loco-regional failure (LRF). Among these patients with LRF, $22(50 \%)$ had non-invasive recurrence and underwent salvage with intravesical treatment (TURBT + intravesical BCG or mitomycin C). Salvage radical cystectomy is the standard treatment for non-responders and invasive recurrent tumors. In our series, salvage cystectomy was performed in nine of these patients with invasive LRF. Patients with noninvasive recurrence after intravesical salvage treatment had better 5-year PFS compared to those with invasive recurrence $(68 \%$ vs $33 \% ; p=0.008)$ and comparable PFS to that of patients without LRF. 

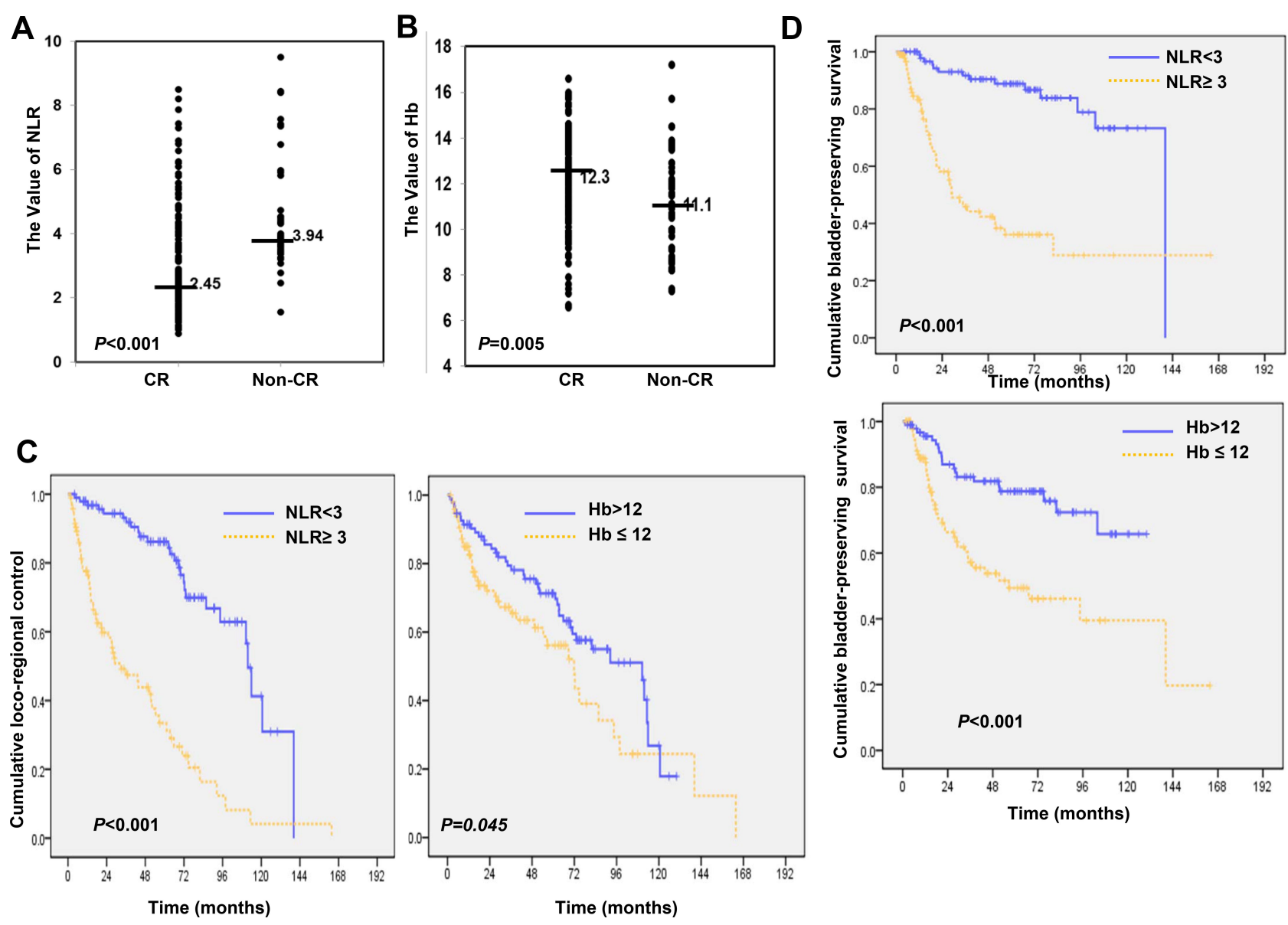

Figure 3 Correlations between the pre-treatment NLR and the prognosis. (A) The difference of NLR values according to the response to bladder-sparing treatment. (B) The difference of $\mathrm{Hb}$ values according to the response to bladder-sparing treatment. (C) The differences of loco-regional control according to the pre-treatment NLR and $\mathrm{Hb}$ (D) The difference of bladder-preservation survival according to the pre-treatment NLR and $\mathrm{Hb}$.

\section{Predictive Role of NLR and $\mathrm{Hb}$ in MIBC Patients}

Evidence suggests that peripheral blood analysis can provide the status of inflammation and anemia and reflect the tumor microenvironment. ${ }^{12,17,18}$ Pre-treatment NLR has been investigated in terms of its capacity to predict clinical outcomes in bladder cancer patients. ${ }^{19-21}$ In the present study, we examined the predictive role of NLR and $\mathrm{Hb}$ for MIBC patients with bladder-sparing treatment. The median pretreatment $\mathrm{Hb}$ and NLR of the overall cohort were $12 \mathrm{~g} / \mathrm{dL}$ and 2.84, respectively. At baseline, 99 patients had a low $\mathrm{Hb}$ $(\leq 12)$ and 94 had a high $\mathrm{Hb}(>12)$, and 95 patients had a high NLR $(\geq 3)$ and 98 had a low NLR $(<3)$. Correlation analysis revealed that a larger NLR was associated with a lower $\mathrm{Hb}$. The relationships between the clinicopathological variables and the pretreatment NLR and $\mathrm{Hb}$ values are shown in Tables 2 and 3 . There were significant differences in survival rate and the $\mathrm{CR}$ rate between the low and high NLR and $\mathrm{Hb}$ groups (Table 2 and Figure 3A-B). According to multivariate analysis for $\mathrm{CR}$, patients received adequate doses of CCRT and had lower NLR associated with higher CR rate (Table 4). Furthermore, in the subgroup of patients with CR, the value of NLR $(p=0.015)$, but not $\mathrm{Hb}(p=0.236)$ correlated with the risk of developing invasive recurrence. According to the comparison of low and high NLR and $\mathrm{Hb}$ subgroups in univariate survival analysis, patients in the high NLR group and lower Hb group had an increased risk of loco-regional recurrence with reduced bladderpreservation rate (Figure $3 \mathrm{C}-\mathrm{D})$ ). According to the results of multivariate analysis (Tables 5 and 6), pretreatment NLR and $\mathrm{Hb}$ were significantly associated with bladderpreservation survival, whereas only NLR had the predictive power for PFS. Furthermore, as shown in Figure 4A-B, pretreatment NLR was significantly correlated with PFS when MIBC patients were stratified by clinical stage, $\mathrm{Hb}$ level and the doses of CCRT. Based on our data, we suggest 
Table 4 Multivariate Analysis to Determine Factors Associated with $C R$

\begin{tabular}{|c|c|c|c|}
\hline Variable & HR & $95 \% \mathrm{Cl}$ & $P$ value \\
\hline \multicolumn{4}{|c|}{ Hydronephrosis } \\
\hline No & Ref & & \\
\hline Yes & 2.326 & $0.69-7.90$ & 0.176 \\
\hline \multicolumn{4}{|c|}{ Chemotherapy } \\
\hline$<2$ cycles & Ref & & \\
\hline$\geq 2$ cycles & 0.359 & $0.13-0.995$ & $0.49 *$ \\
\hline \multicolumn{4}{|l|}{ RT dose } \\
\hline$<56 \mathrm{~Gy}$ & Ref & & \\
\hline$\geq$ 56Gy & 0.038 & $0.14-0.105$ & $<0.00 I^{*}$ \\
\hline \multicolumn{4}{|l|}{$\mathbf{H b}$} \\
\hline$\leq 12$ & Ref & & \\
\hline$>12$ & 0.608 & $0.22-1.66$ & 0.33 \\
\hline \multicolumn{4}{|l|}{ NLR } \\
\hline$<3$ & Ref & & \\
\hline$\geq 3$ & 11.63 & $4.09-33.04$ & $<0.001 *$ \\
\hline
\end{tabular}

Notes: *Statistical significance.

that MIBC patients with higher NLR require more aggressive treatment and close follow-up.

\section{Discussion}

A growing body of evidence suggests that bladder-sparing treatment for MIBC is a reliable option with good oncologic outcomes in selected patients. ${ }^{9,22}$ This was a retrospective study of the factors influencing the treatment outcomes of MIBC patients treated with bladdersparing treatment, using the data of cancer registry and death registration in our hospital. An advantage of our analysis is that the results are based on a relative large population of MIBC patients with information regarding tumor histology, staging and primary treatment detail. Bladder cancer occurs most commonly in the elderly. It has been reported that the 5-year overall survival rate of bladder cancer treated with CMT is $45 \sim 60 \%$, and significantly decrease with advanced age and poor performance status. ${ }^{8,10}$ In our series, the 5-year OS rate was $64 \%$, and older age ( $\geq 70$ years) and poor performance status was associated with a marked decrease in OS and PFS rates. A higher risk of treatment failure was reported in patients with locally advanced MIBC compared to those of stage T2N0M0. ${ }^{4,22}$ We demonstrated that the 5-year PFS
Table 5 Adjusted Hazard Ratio of Determine Factors Associated with Bladder-Preserving Survival for Patients with MIBC

\begin{tabular}{|c|c|c|c|}
\hline Variable & HR & $95 \% \mathrm{Cl}$ & $P$ value \\
\hline \multicolumn{4}{|l|}{ ECOG } \\
\hline$\leq 1$ & Ref & & \\
\hline$>1$ & 1.78 & $0.94-3.37$ & 0.079 \\
\hline \multicolumn{4}{|l|}{ Hydronephrosis } \\
\hline No & Ref & & \\
\hline Yes & 3.17 & $1.56-6.44$ & $0.001 *$ \\
\hline \multicolumn{4}{|l|}{ Clinical stage } \\
\hline T2NOMO & Ref & & \\
\hline Advanced $^{c}$ & 1.63 & $0.92-2.87$ & 0.093 \\
\hline \multicolumn{4}{|l|}{ NLR } \\
\hline$<3$ & Ref & & \\
\hline$\geq 3$ & 2.63 & $1.31-5.30$ & $0.007^{*}$ \\
\hline \multicolumn{4}{|l|}{ CCRT } \\
\hline Inadequate doses & Ref & & \\
\hline Adequate doses ${ }^{d}$ & 0.36 & $0.18-0.69$ & $0.002 *$ \\
\hline \multicolumn{4}{|l|}{$\mathrm{Hb}$} \\
\hline$\leq 12$ & Ref & & \\
\hline$>12$ & 0.45 & $0.25-0.82$ & $0.009 *$ \\
\hline \multicolumn{4}{|l|}{ Treatment response ${ }^{\mathrm{b}}$} \\
\hline CR & Ref & & \\
\hline Non-CR & 2.07 & $1.02-4.24$ & $0.046^{*}$ \\
\hline
\end{tabular}

Notes: ${ }^{c}=$ Clinical stage $\mathrm{T} 3-\mathrm{T} 4$ or clinical regional $\mathrm{LN}$ involvement. ${ }^{\mathrm{d}}=\mathrm{C} / \mathrm{T} \geq 2$ cycles combined with RT dose $\geq 56 \mathrm{~Gy} .{ }^{\mathrm{b}}=$ Response to bladder-sparing treatment. *Statistical significance.

survival rate was $70 \%$ for patients with stage cT2N0M0 and 59\% with stage T3-T4 or clinical LN involvement.

At present, bladder-preserving CMT is recommended for patients with favorable baseline characteristics. A subset of patients who achieved CR after CMT exhibited an equivalent probability of long-term survival; this may allow patients to retain their native bladder. A large body of experience suggests that bladder-sparing approaches yield favorable results in appropriately selected patients, with CR rates of $70 \%$ to $80 \%$, 5-year OS rates of $50 \%$ to $60 \%$, and survival rates with an intact bladder of $40 \%$ to $45 \% .^{23,24}$ In our series, the CR rate was $76 \%$, and the 5-year PFS and bladder-preservation survival rates were $52 \%$ and $64 \%$, respectively. Increased RT dose and combination with chemotherapy were associated with an increased $\mathrm{CR}$ rate. In patients who achieve $\mathrm{CR}$ after 
Table 6 Adjusted Hazard Ratio of Determine Factors Associated with PFS

\begin{tabular}{|c|c|c|c|}
\hline Variable & HR & $95 \% \mathrm{Cl}$ & $P$ value \\
\hline \multicolumn{4}{|l|}{ ECOG } \\
\hline$\leq 1$ & Ref & & \\
\hline$>1$ & 1.52 & $0.90-2.56$ & 0.117 \\
\hline \multicolumn{4}{|l|}{ Hydronephrosis } \\
\hline No & Ref & & \\
\hline Yes & 1.68 & $0.92-3.08$ & 0.091 \\
\hline \multicolumn{4}{|l|}{ Clinical stage } \\
\hline T2NOMO & Ref & & \\
\hline Advanced $^{c}$ & 2.01 & $1.26-3.20$ & $0.003^{*}$ \\
\hline \multicolumn{4}{|l|}{ NLR } \\
\hline$<3$ & Ref & & \\
\hline$\geq 3$ & 3.16 & $1.08-5.56$ & $<0.001 *$ \\
\hline \multicolumn{4}{|l|}{ CCRT } \\
\hline Inadequate doses & Ref & & \\
\hline Adequate doses $^{\mathrm{d}}$ & 3.25 & $0.14-0.44$ & $<0.001 *$ \\
\hline \multicolumn{4}{|l|}{ Treatment response ${ }^{b}$} \\
\hline CR & Ref & & \\
\hline Non-CR & 1.95 & $1.13-3.38$ & $0.017^{*}$ \\
\hline \multicolumn{4}{|l|}{$\mathrm{Hb}$} \\
\hline$\leq 12$ & Ref & & \\
\hline$>12$ & 0.67 & $0.42-1.05$ & 0.079 \\
\hline
\end{tabular}

Notes: ${ }^{c}=$ Clinical stage $\mathrm{T} 3-\mathrm{T} 4$ or clinical regional $\mathrm{LN}$ involvement. ${ }^{\mathrm{d}}=\mathrm{C} / \mathrm{T} \geq 2$ cycles combined with RT dose $\geq 56 \mathrm{~Gy} .{ }^{\mathrm{b}}=$ Response to bladder-sparing treatment. *Statistical significance.

bladder-sparing treatment, there is a $13 \%$ to $40 \%$ risk of intravesical recurrence (non-invasive or invasive). ${ }^{24,25}$ Half of the cases of LRF were of non-invasive recurrence and were salvaged with intravesical treatment. Moreover, patients with non-invasive recurrence after intravesical salvage treatment had better 5-year PFS compared to those with invasive recurrence $(68 \%$ vs $33 \% ; p=0.008)$ and comparable PFS to that of patients without LRF. Several prior studies addressed the management of noninvasive recurrence after $\mathrm{CR}$ to $\mathrm{CMT}^{24-26}$ Based on the findings of the present study, intravesical instillation for bladder preservation had reasonable efficacy in patients with non-invasive bladder recurrence.

Systemic inflammation is a recognized characteristic of malignancy, and numerous inflammatory markers have been investigated as prognostic indicators for cancer patients. Host inflammatory responses also play an important role in tumor development and progression. Regarding urothelial cell carcinoma, it has been reported that elevation of C-reactive protein and IL-6 before treatment predicts a poor prognosis in patients with muscle-invasive bladder cancer. ${ }^{27}$ Increasing evidence has suggested that neutrophils play an important role in the host response to cancer. The NLR is an inflammatory and immunologically based index. ${ }^{28}$ An association between blood NLR and disease progression has been demonstrated in numerous malignancies. ${ }^{11,13}$ High NLR is reported to be negatively correlated with survival in urothelial carcinoma. Evidence has shown that pre-treatment high NLR, implicating higher incidences of lymph node metastasis or more advanced stage, was associated with worse survival for MIBC patients treated with radical cystectomy. ${ }^{15,17,19}$ Moreover, it has recently been indicated that NLR is a useful predictor for the response to neoadjuvant chemotherapy in MIBC. ${ }^{29,30}$ However, the clinical utility of pre-treatment NLR as a predictive biomarker in CMT needs further investigation. In addition, studies have shown that low preoperative hemoglobin $(\mathrm{Hb})$ is associated with poor prognosis for colorectal cancer and MIBC patients. ${ }^{17,31}$ Tumor-related anemia has received attention because a hypoxic microenvironment is likely to promote tumor invasiveness. ${ }^{18}$ Accordingly, we examined the predictive role of peripheral blood indexes including NLR and $\mathrm{Hb}$ in MIBC patients treated with bladder-sparing treatment. Our data revealed that an elevated pretreatment NLR was significantly associated with increased risk of developing locoregional recurrence and distant metastasis, whereas the value of $\mathrm{Hb}$ was not correlated with the risk of disease failure. Furthermore, pretreatment higher NLR and lower $\mathrm{Hb}$ were associated with poor treatment response and lower bladder preservation rate. In the subgroup of CR patients, higher NLR was linked to the risk of invasive recurrence. According to the results of univariate and multivariate analyses, pretreatment NLR $\geq 3$ was associated with shorter PFS compared to NLR $<3$. The development of evidence-based criteria for selection of patients for bladder cancer treatment is important. We demonstrated that higher NLR was associated with increased tumor burden and invasiveness, and had the predictive power for treatment response to bladdersparing treatment. Based on the data, we suggest MIBC patients with higher NLR require more aggressive treatment and closer follow-up. Bladder-sparing treatment could be suggested for MIBC patients with lower NLR based on the higher $\mathrm{CR}$ rate and better survival rate. 
A

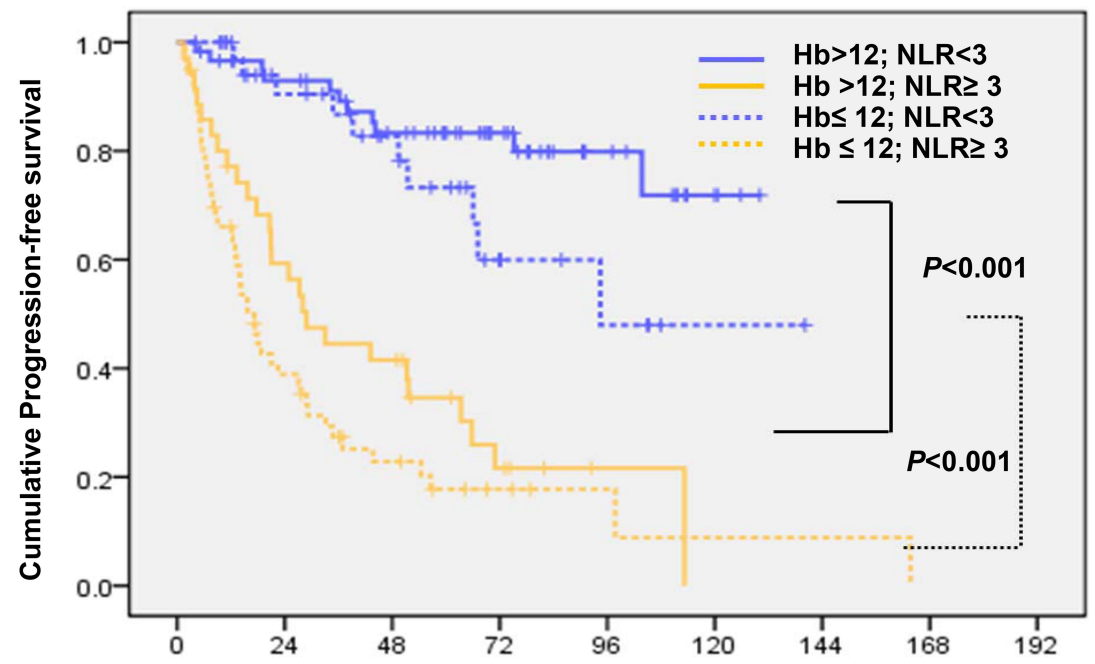

B

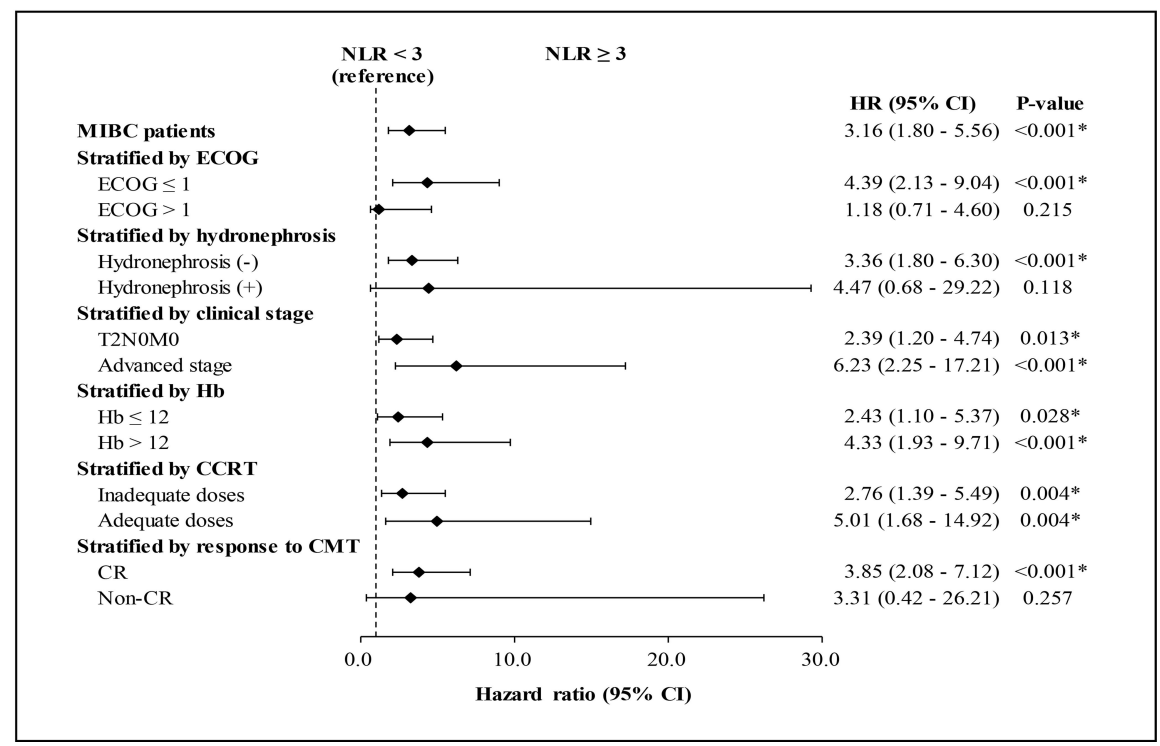

Figure 4 Correlations between the PFS and the value of NLR and $\mathrm{Hb}$. (A) The difference of PFS according to the value of NLR stratified by $\mathrm{Hb}$ (solid line, Hb> 2 ; dotted line, $\mathrm{Hb} \leq 12$; blue, NLR<3; yellow, NLR $\geq 3$ ). (B) NLR associated with PFS when MIBC patients were stratified by clinical factors in multivariate model. * $p<0.05$.

The limitations of our study are inherent to investigations based on hospital registries. We were unable to ascertain the reasons for delays in the initiation of curative treatment or the choice of palliative treatment. Furthermore, we could not adjust for potential unmeasured selection biases regarding performance status, access to healthcare, or other patient-related factors.

\section{Conclusions}

Among patients with MIBC treated with bladder-sparing treatment, adequate CCRT and lower NLR correlate with better PFS, particularly for patients with good performance status. Furthermore, NLR could be used as a biomarker for prognostic assessment, and to assist the clinician and patient in making an informed decision regarding treatment options for MIBC.

\section{Acknowledgment}

The authors thank Meng-Hung Lin, $\mathrm{PhD}$, and Health Information and Epidemiology Laboratory, Chang Gung Memorial Hospital, Chiayi Branch for providing comments and assistance in data analysis.

\section{Funding}

The work was support by Chang Gung Memorial Hospital. Grant CGRPG6J0021 (to M.F. Chen). 


\section{Disclosure}

The authors declare that they have no conflicts of interest for this work.

\section{References}

1. Witjes JA, Comperat E, Cowan NC, et al. EAU guidelines on muscle-invasive and metastatic bladder cancer: summary of the 2013 guidelines. Eur Urol. 2014;65(4):778-792. doi:10.1016/j. eururo.2013.11.046

2. Gakis G, Efstathiou J, Lerner SP, et al. ICUD-EAU International Consultation on Bladder Cancer 2012: radical cystectomy and bladder preservation for muscle-invasive urothelial carcinoma of the bladder. Eur Urol. 2013;63(1):45-57. doi:10.1016/j.eururo.2012.08.009

3. Mathieu R, Lucca I, Klatte T, Babjuk M, Shariat SF. Trimodal therapy for invasive bladder cancer: is it really equal to radical cystectomy? Curr Opin Urol. 2015;25(5):476-482. doi:10.1097/ MOU.0000000000000203

4. Hautmann RE, de Petriconi RC, Pfeiffer C, Volkmer BG. Radical cystectomy for urothelial carcinoma of the bladder without neoadjuvant or adjuvant therapy: long-term results in 1100 patients. Eur Urol. 2012;61(5):1039-1047. doi:10.1016/j.eururo.2012.02.028

5. Stein JP, Lieskovsky G, Cote R, et al. Radical cystectomy in the treatment of invasive bladder cancer: long-term results in 1054 patients. J Clin Oncol. 2001;19(3):666-675. doi:10.1200/ JCO.2001.19.3.666

6. Shabsigh A, Korets R, Vora KC, et al. Defining early morbidity of radical cystectomy for patients with bladder cancer using a standardized reporting methodology. Eur Urol. 2009;55 (1):164-174. doi:10.1016/j.eururo.2008.07.031

7. Grossman HB, Natale RB, Tangen CM, et al. Neoadjuvant chemotherapy plus cystectomy compared with cystectomy alone for locally advanced bladder cancer. $N$ Engl J Med. 2003;349 (9):859-866. doi:10.1056/NEJMoa022148

8. Ploussard G, Daneshmand S, Efstathiou JA, et al. Critical analysis of bladder sparing with trimodal therapy in muscle-invasive bladder cancer: a systematic review. Eur Urol. 2014;66(1):120-137. doi:10.1016/j.eururo.2014.02.038

9. Efstathiou JA, Bae K, Shipley WU, et al. Late pelvic toxicity after bladder-sparing therapy in patients with invasive bladder cancer: RTOG 89-03, 95-06, 97-06, 99-06. J Clin Oncol. 2009;27 (25):4055-4061. doi:10.1200/JCO.2008.19.5776

10. Mitin T, George A, Zietman AL, et al. Long-term outcomes among patients who achieve complete or near-complete responses after the induction phase of bladder-preserving combined-modality therapy for muscle-invasive bladder cancer: a pooled analysis of NRG oncology/ RTOG 9906 and 0233. Int J Radiat Oncol Biol Phys. 2016;94 (1):67-74. doi:10.1016/j.ijrobp.2015.09.030

11. Chen MF, Chen PT, Kuan FC, Chen WC. The predictive value of pretreatment neutrophil-to-lymphocyte ratio in esophageal squamous cell carcinoma. Ann Surg Oncol. 2019;26(1):190-199. doi:10.1245/ s10434-018-6944-1

12. Treffers LW, Hiemstra IH, Kuijpers TW, van den Berg TK, Matlung HL. Neutrophils in cancer. Immunol Rev. 2016;273 (1):312-328. doi:10.1111/imr.12444

13. Moses K, Brandau S. Human neutrophils: their role in cancer and relation to myeloid-derived suppressor cells. Semin Immunol. 2016;28(2):187-196. doi:10.1016/j.smim.2016.03.018

14. Tang $X$, Wang S, An C, Du P, Yang Y. Preoperative high neutrophil-to-lymphocyte ratio is associated with high-grade bladder cancer. Anticancer Res. 2017;37:4659-4663.

15. Ojerholm E, Smith A, Hwang WT, et al. Neutrophil-to-lymphocyte ratio as a bladder cancer biomarker: assessing prognostic and predictive value in SWOG 8710. Cancer. 2017;123(5):794-801. doi:10.1002/cncr.30422
16. Contal C, O'Quigley J. An application of changepoint methods in studying the effect of age on survival in breast cancer. Comput Stat Data Anal. 1999;30(3):253-270. doi:10.1016/S0167-9473(98) 00096-6

17. Zhang J, Zhou X, Ding $\mathrm{H}$, et al. The prognostic value of routine preoperative blood parameters in muscle-invasive bladder cancer. BMC Urol. 2020;20(1):31. doi:10.1186/s12894-020-00602-9

18. Leo C, Giaccia AJ, Denko NC. The hypoxic tumor microenvironment and gene expression. Semin Radiat Oncol. 2004;14(3):207-214. doi:10.1016/j.semradonc.2004.04.007

19. Hu G, Xu F, Zhong K, et al. The prognostic role of preoperative circulating neutrophil-lymphocyte ratio in primary bladder cancer patients undergoing radical cystectomy: a meta-analysis. World J Urol. 2018.

20. Tang X, Du P, Yang Y. The clinical use of neutrophil-to-lymphocyte ratio in bladder cancer patients: a systematic review and meta-analysis. Int J Clin Oncol. 2017;22(5):817-825. doi:10.1007/ s10147-017-1171-5

21. Morizawa Y, Miyake M, Shimada K, et al. Correlation of immune cells and cytokines in the tumor microenvironment with elevated neutrophil-to-lymphocyte ratio in blood: an analysis of muscle-invasive bladder cancer. Cancer Invest. 2018;36 (7):395-405. doi:10.1080/07357907.2018.1506800

22. Chung PW, Bristow RG, Milosevic MF, et al. Long-term outcome of radiation-based conservation therapy for invasive bladder cancer. Urol Oncol. 2007;25(4):303-309. doi:10.1016/j.urolonc.2006.09.015

23. Arcangeli G, Strigari L, Arcangeli S. Radical cystectomy versus organ-sparing trimodality treatment in muscle-invasive bladder cancer: a systematic review of clinical trials. Crit Rev Oncol Hematol. 2015;95(3):387-396. doi:10.1016/j.critrevonc.2015.04.006

24. Sanchez A, Wszolek MF, Niemierko A, et al. Incidence, clinicopathological risk factors, management and outcomes of nonmuscle invasive recurrence after complete response to trimodality therapy for muscle invasive bladder cancer. J Urol. 2018;199(2):407-415. doi:10.1016/j.juro.2017.08.106

25. Sapre N, Anderson P, Foroudi F. Management of local recurrences in the irradiated bladder: a systematic review. BJU Int. 2012;110(Suppl 4):51-57. doi:10.1111/j.1464-410X.2012.11476.x

26. Zietman AL, Grocela J, Zehr E, et al. Selective bladder conservation using transurethral resection, chemotherapy, and radiation: management and consequences of $\mathrm{Ta}, \mathrm{T} 1$, and Tis recurrence within the retained bladder. Urology. 2001;58(3):380-385. doi:10.1016/S00904295(01)01219-5

27. Yoshida S, Saito K, Koga F, et al. C-reactive protein level predicts prognosis in patients with muscle-invasive bladder cancer treated with chemoradiotherapy. BJU Int. 2008;101(8):978-981. doi:10.1111/j.1464-410X.2007.07408.x

28. Dumitru CA, Moses K, Trellakis S, Lang S, Brandau S. Neutrophils and granulocytic myeloid-derived suppressor cells: immunophenotyping, cell biology and clinical relevance in human oncology. Cancer Immunol Immunother. 2012;61(8):1155-1167. doi:10.1007/ s00262-012-1294-5

29. Black AJ, Zargar H, Zargar-Shoshtari K, et al. The prognostic value of the neutrophil-to-lymphocyte ratio in patients with muscle-invasive bladder cancer treated with neoadjuvant chemotherapy and radical cystectomy. Urol Oncol. 2020;38(1):3 e17-13 e27. doi:10.1016/j.urolonc.2019.09.023

30. Suh J, Jung JH, Jeong CW, Kwak C, Kim HH, Ku JH. Clinical significance of pre-treated neutrophil-lymphocyte ratio in the management of urothelial carcinoma: a systemic review and meta-analysis. Front Oncol. 2019;9:1365. doi:10.3389/ fonc. 2019.01365

31. Wilson MJ, van Haaren M, Harlaar JJ, et al. Long-term prognostic value of preoperative anemia in patients with colorectal cancer: a systematic review and meta-analysis. Surg Oncol. 2017;26 (1):96-104. doi:10.1016/j.suronc.2017.01.005 


\section{Publish your work in this journal}

Cancer Management and Research is an international, peer-reviewed open access journal focusing on cancer research and the optimal use of preventative and integrated treatment interventions to achieve improvec outcomes, enhanced survival and quality of life for the cancer patient.
The manuscript management system is completely online and includes a very quick and fair peer-review system, which is all easy to use. Visit http://www.dovepress.com/testimonials.php to read real quotes from published authors. 